\title{
Automatic Tube Compensation: Is It Worthwhile?
}

The influence of the endotracheal tube (ETT) during weaning has been questioned. Concerns about the work of breathing (WOB) imposed by the ETT have led to the use of various corrective methods and ventilatory modes to overcome ETT resistance. Despite the theoretical advantages of different approaches, such as pressure support (PSV) and/or automatic tube compensation (ATC), no methods appear to provide superior performance, and the question of the clinical relevance of such a concept still remains controversial. ${ }^{1}$

The presence of an ETT is commonly presumed to augment respiratory load in spontaneously breathing patients who are receiving mechanical ventilation. ${ }^{2}$ But the WOB imposed by an ETT also depends on the patient's effort, while resistance depends on flow rate and ventilatory mode, and is of course proportional to the inner diameter and length of the ETT. PSV was initially proposed to compensate for such increased resistance. However, a patient's inspiratory flow is itself highly variable from breath to breath. Therefore, PSV cannot provide constant adjustments in response to resistance caused by changes in the patient's inspiratory effort. ATC was thus originally developed to overcome such bias and to achieve optimal tube compensation via a closed-loop control of tracheal pressure. ${ }^{3}$

If ATC can be considered as a safe procedure, ${ }^{4}$ its use in clinical routine yet remains controversial, whereas, compared to other spontaneous breathing trial methods, it has never been shown to hasten liberation from mechanical ventilation. In a randomized trial, Maeda and co-workers concluded in 2003 that ATC was not able to overcome the pressure-time product associated with triggering, and that PSV was as effective as ATC at $100 \% .^{5}$

See the Original Study on Page 697

In this issue of Respiratory CARe, Oto and co-workers investigate, in a very interesting physiological bench test, whether ATC could provide effective respiratory work-load relief in used ETTs. ${ }^{6}$ The median duration of mechanical ventilation in their study group (median use of the ETT prior to extubation and measurements) was 5 days. During their study, ATC was set at $100 \%$, with a PEEP of $5 \mathrm{~cm} \mathrm{H}_{2} \mathrm{O}$. In all cases, the pressure-time product values increased with tidal volume during ATC, and this increase was also variable according to the ETT use. They conclude that care should be taken when using ATC during the weaning period, especially in patients with massive bronchorrhea undergoing long-term mechanical ventilation, whereas in such cases it may underestimate the real level of compensation needed to overcome ETT resistance.

The good question may also be whether overcoming ETT resistances is really necessary to prove a patient's readiness for extubation. In a very nice physiological study, on successfully extubated patients, Strauss and co-workers demonstrated that a 2-hour trial of spontaneous breathing through an ETT well mimicked the WOB performed after extubation. ${ }^{7}$ In their study, the WOB dissipated against the ETT represented around $10 \%$ of the overall work performed by the patient, but this increased work load was not different from what was related to upper airways obstruction immediately following extubation. Their study included a heterogeneous population of patients under mechanical ventilation for a mean $7.6 \pm 6.1$ days duration, and so patients who may also have experienced a decrease of the ETT inner diameter related to secretions. According to their results, one may consider that either an ATC or a PSV trial may not be mandatory during weaning, or, most of all, that the use of such a compensatory mode may in fact falsify spontaneous breathing trial relevance.

The question of the most adequate way to perform spontaneous breathing trials is still unanswered, but "the best is (certainly) yet to come!" The future may provide us several new technological approaches for the weaning process and perhaps new closed-loop techniques that will improve outcome in our setting of interest.

Erwan L'Her MD PhD

Réanimation Médicale et Urgences Adultes Centre Hospitalier Universitaire de la Cavale Blanche Laboratoire de Traitement de l'Information Médicale INSERM UMR 1101 LATIM Université de Bretagne Occidentale Brest, France

\section{REFERENCES}

1. Branson RD. Endotracheal tubes and imposed work of breathing: what should we do about it, if anything? Critical Care 2003;7(5): 347-348. 


\section{Automatic Tube Compensation: Is It Worthwhile?}

2. Shapiro M, Wilson RK, Casar G, Bloom K, Teague RB. Work of breathing through different sized endotracheal tubes. Crit Care Med 1986;14(12):1028-1031.

3. Guttmann J, Eberhard L, Fabry B, Bertschmann W, Wolff G. Continuous calculation of intratracheal pressure in tracheally intubated patients. Anesthesiology 1993;79(3):503-513.

The author has disclosed no conflicts of interest.

Correspondence: Erwan L’Her MD PhD, Réanimation Médicale et Urgences Adultes, Centre Hospitalier Universitaire de la Cavale Blanche, 29609 Brest, France. E-mail: erwan.lher@chu-brest.fr.

DOI: $10.4187 /$ respcare.01865
4. Figueroa-Casas JB, Montoya R, Arzabala A, Connery SM. Comparison between automatic tube compensation and continuous positive airway pressure during spontaneous breathing trials (SBTs). Respir Care 2010;55(5):549-554.

5. Maeda Y, Fujino Y, Uchiyama A, Taenaka N, Mashimo T, Nishimura M. Does the tube-compensation function of two modern mechanical ventilators provide effective work of breathing relief? Crit Care 2003; 7(5):R92-R97.

6. Oto J, Imanaka H, Nakataki E, Ono R, Nishimura M. Potential inadequacy of automatic tube compensation to decrease inspiratory work load after at least 48 hours of endotracheal tube use in the clinical setting. Respir Care 2012;57(5):697-703.

7. Strauss C, Louis B, Isabey D, Lemaire F, Harf A, Brochard L. Contribution of the endotracheal tube and the upper airway to breathing workload. Am J Respir Crit Cared Med 1998;157(1): 23-30. 